\title{
An Infectious Cause of Esophagobronchial Fistula
}

\author{
Abdul Basit Ibne Momen, Rafa Faaria Alam, Farhana Khan, Sadia Saber, and Md Tarek Alam
}

\section{ABSTRACT}

\begin{abstract}
An infected cause of esophagobronchial fistula between left bronchus and esophagus is mentioned who is a 32 year old male with a history of smoking and I/V drug abuse. The scientific reasons for suspecting an esophagogastric-bronchial fistula in an adult are discussed, as well as a description of the different etiologies of this condition. Intra thoracic malignancy, injuries, and infections are the most frequent causes of esophageal-bronchial fistula. These fistulas are caused by the rupturing of caseous peribronchial lymph nodes into adjacent structures such as the esophagus and bronchi. It's difficult to determine what the right course of action is. Such cases are surgically treated, while others can only be treated conservatively. Diagnosing bronchoesophageal fisula is usually challenging and often delayed, since there have not been many cases found. Any patient who presents with cough after deglutition should be suspected of having an esophagobronchial fistula, and tubercular origin should also be considered, particularly in an endemic region, since early diagnosis and treatment with anti-tubercular therapy typically results in resolution.
\end{abstract}

Keywords: Tuberculosis, Oesophagobronchial fistula.
Submitted : April 24, 2021

Published : May 15, 2021

ISSN: $2593-8339$

DOI: $10.24018 /$ ejmed.2021.3.3.831

\section{A. B. I. Momen*}

Registrar, Department of Medicine, Bangladesh Medical College, Dhaka, Bangladesh.

(e-mail: abdulbasit17@gmail.com)

R. F. Alam

Assistant Registrar, Department of Medicine, Bangladesh Medical College, Dhaka, Bangladesh.

(e-mail: rafa.alam27@gmail.com)

F. Khan

Senior Lecturer, Department of

Pharmacology, Ad-Din Women's Medical College, Dhaka, Bangladesh.

(e-mail: farhanakhan488@gmail.com)

S. Saber

Assistant Professor, Department of Medicine, Bangladesh Medical College, Dhaka, Bangladesh.

(e-mail: sadiasaber201477@gmail.com)

M. T. Alam

Professor and Head, Department of Medicine, Bangladesh Medical College, Dhaka, Bangladesh.

(e-mail: mtarekalam16@gmail.com)

*Corresponding Author

\section{INTRODUCTION}

The most common cause of esophagobronchial fistula is intra thoracic malignancy followed by trauma and infections. Despite their more frequent appearance, acquired esophagobronchial fistulas have gained less recognition in the recent medical literature than congenital communications between the esophagus and the respiratory tree. This is unquestionably due to the fact that the vast majority of acquired fistulas are a late and terminal symptom of an underlying malignant phase, most often esophageal carcinoma. Acquired non-malignant esophagobronchial fistulas are far more uncommon and fall into two categories: traumatic and infective [1]. Infectious fistulas are more prevalent, accounting for around two-thirds of all recorded cases. Traumatic fistulas, which account for the remaining one-third, are typically triggered by perforating foreign bodies, inserting instruments, or traumatic injury [2]. Cases in the infectious population were often attributed to tuberculosis and syphilis as reported by the past [3]. Many of the cases historically known as "indeterminate aetiology" may fall into this category. Those of infective cause are mostly because of granulomatous inflammation of mediastinal lymph nodes. The most common causative organisms are Mycobacterium tuberculosis, Histoplasma, and Actinomyces [3].

The pathology of bronchoesophageal fistulas tubercular origin is of considerable interest. These fistulas result from rupturing of casseous peribronchial lymph nodes into neighboring structures such as the esophagus and the bronchi may cause these fistulas [3]. The tuberculous mediastinal lymph nodes may either push on the deformed wall of the bronchus with the production of submucosal caseous prominences which project abruptly to the bronchial lumen or penetrate the bronchial mucous membrane [4]. The best course of management is unclear. While certain cases have been managed surgically [5] others reported successful resolution of the fistula with medical management alone [6] if tuberculous esophagobronchial fistula is diagnosed early 
[7]. Here we present a case of a young patient with tuberculosis-related esophagobronchial fistulas who had history of immunodeficiency who responded well to medical treatment.

\section{CASE REPORT}

A 32-year-old Asian male IV drug abuser and smoker presented to the outpatient department with low grade fever, weight loss for 1 month and dry cough whenever he consumed food, both liquid and solid. There was no vomiting, hematemesis, shortness of breath, chest pain or choking. There was also no history of foreign body aspiration, ingestion of toxic or corrosive substances or any surgical procedures in past. Physical examination was unremarkable.

On investigation $\mathrm{CBC}$ revealed $\mathrm{WBC} 6,000 / \mathrm{cmm}$, with $82 \%$ neutrophils and $15 \%$ lymphocytes, haemoglobin 9.2 $\mathrm{g} / \mathrm{dL}$, platelet $280,000 / \mathrm{cmm}$ and ESR was $100 \mathrm{~mm}$ in the first hour. Renal and liver function tests were within normal limits including chest X-ray. HIV serology was negative. Endoscopy was performed and showed multiple ulcers with fibrotic scars with probable fistulous opening seen at the mid esophagus extending between $27 \mathrm{~cm}$ to $32 \mathrm{~cm}$ distance from the incisor teeth (Fig. 1). Multiple biopsies were taken. Following this an oral gastrograffin contrast X-ray was done which showed a fistula (Fig. 2) between the left main bronchus and esophagus. The biopsy report showed caseating granuloma confirming Tuberculosis.

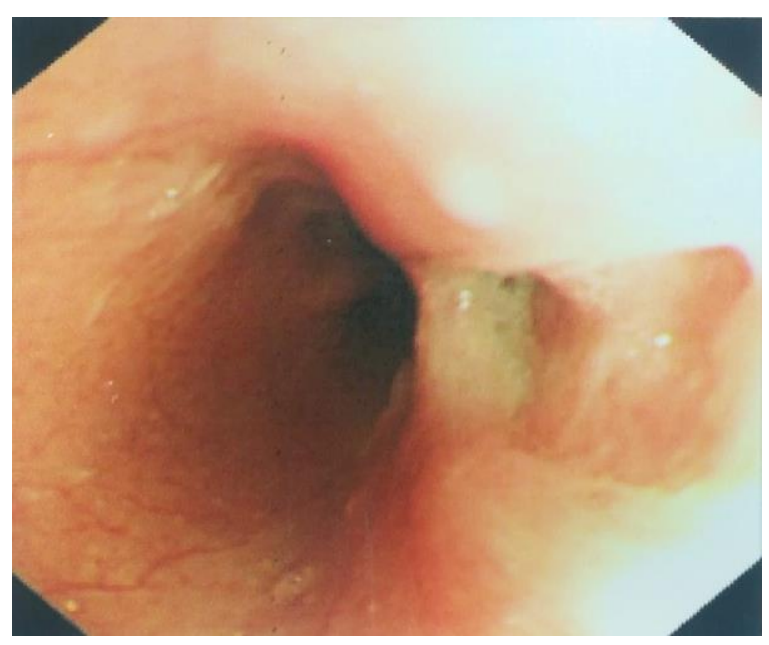

Fig. 1. Visualization of the fistulous opening in the esophagus.

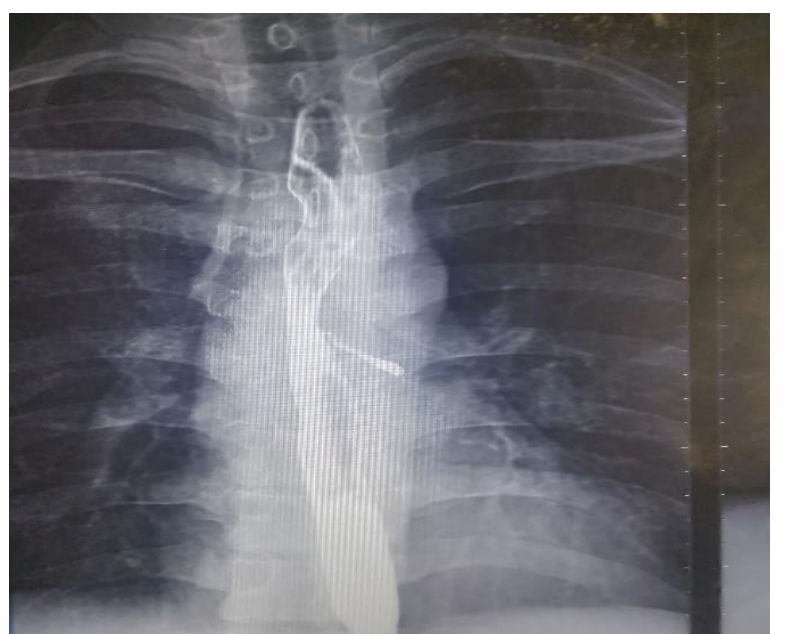

Fig. 2. Contrast X-ray showing contrast leaking into the left main bonchi.
The patient was managed by nasogastric feeding and was started on standard anti-tubercular therapy with Rifampicin, Isoniazid, Pyrazinamide and Ethambutol according to weight together with vitamin B6. After 4 months of treatment the patients cough improved and repeat endoscopy showed resolution of the ulcers and the fistula. He completed 6 months treatment and made an uneventful recovery.

\section{DISCUSSION}

Tuberculosis-related bronchoesophageal fistulas are uncommon [8]. Just 37 cases have been reported in the literature to our knowledge from 1893 to 2001, ages between 36 to 85 . Among them 22 cases showed no information regarding the treatment, 12 cases seek medical treatment and only 3 cases needed surgical management [9]. And just a handful of cases were reported after that to the best of our knowledge. Tuberculous BEF in children is unusual and has been linked to a high mortality rate in studies [10]. Fistulae vary in size and location, according to most reports, the lower third of the esophagus, which communicates with the right bronchial tree, is the most common position, [11] and the most frequent symptoms include chronic and paroxysmal fever, dysphagia, cough, and pneumonia [11]-[13]. Patients experience bouts of cough after drinking liquids (Ono's sign), which is a common symptom. Recurrent lower respiratory tract infections, haemoptysis, and retrosternal lung pain are among the signs that certain patients experience [14]. Due to the absence of clear signs or symptoms, BEF diagnosis is generally difficult and sometimes delayed. These fistulae have been related to the presence of tuberculous mediastinal adenopathy, which induces necrosis and perforation of the adjacent structures, providing the conditions for fistula formation [8], [15], [16]. The presence of the mediastinal lymph nodes has been suggested as a pathway for the formation of a BEF in tuberculosis. Inflammation of the tracheobronchial tree and esophagus causes abscess rupture and caseous necrosis, or fibrous scar formation causes traction diverticulum of the esophagus and resulting fistula formation at the diverticulum's edge. A number of cases of tuberculous BEF associated with HIV infection have been identified in recent years [9]. The most common treatment for esophageal-bronchial fistula is surgery, which involves dividing the fistulous tract and removing some part of the lung that has been irreversibly compromised by the suppurative phase. Simple ligation and resection of the fistulous tract may be done if the fistulous tract originates from lymph nodes with no parenchymal complication [17] Surgical care was not needed in our case. In a related report, antituberculosis chemotherapy and nasogastric feeding culminated in the recovery of bronchoesophageal fistulas in three patients who were HIV positive [6].

\section{CONCLUSION}

A high degree of suspicion of esophagobronchial fistula should be present with any patient who presents with cough after deglutition, and tubercular origin should also be kept in mind especially in an endemic area as early diagnosis and initiation of treatment with anti-tubercular therapy usually leads to resolution. 


\section{REFERENCES}

[1] Hutchin P, Lindskog GE. Acquired esophagobronchial fistula of infectious origin. Journal of Thoracic and Cardiovascular Surgery. 1964; 48 (1): 1-2.

[2] Hughes Jr FA, Fox Jr JR. Acquired nonmalignant esophagotracheobronchial fistula: report of two cases. Journal of Thoracic Surgery. 1954 Apr 1; 27(4): 384-9.

[3] Coleman, F.P. and Bunch Jr, G.H., 1950. Acquired nonmalignant esophagotracheobronchial fistula. Journal of Thoracic Surgery, 19(4), pp.542-558.

[4] Frostad S. Segmental atelectasis in children with primary tuberculosis. Am Rev Respir Dis 1959; 79: 597-605.

[5] P. Rosario, J. Song, W. Wittenborn, F. Christian. Tracheoesophageal fistula in AIDS: stent versus primary repair. AIDS Patient Care STDs, 10 (1996), pp. 334-335.

[6] Porter J.C., Friedland J.S., Freedom A.R. Tuberculous bronchoesophageal fistulae in patients with the human immunodeficiency virus: three case report and review. Clin Infect Dis. 1994; 19: 954-957.

[7] Lee J.H., Shin D.H., Kand K.W. The medical treatment of a tuberculous tracheo-oesophageal fistula. Tuber Lung Dis. 1992; 73: 177-179.

[8] Wigley FM, Murray HW, Mann RB, Saba GP, Kashima H, Mann JJ: Unusual manifestation of tuberculosis: TE fistula. Am J Med 1976; 60: 310-314.

[9] Lado FL, Gomez AG, de Barron AC, López JA. Bronchoesophageal fistulae secondary to tuberculosis. Respiration. 2002; 69(4): 362-5.

[10] Goussard P, Sidler D, Kling S, et al. Esophageal stent improves ventilation in a child with a broncho-esophageal fistula caused by Mycobacterium tuberculosis. Pediatr Pulmonol 2007; 42: 93-7.

[11] Risher WH, Arensman RM, Ochsner JL. Congenital bronchoesophageal fistula. Ann Thorac Surg 1990; 49: 500-5.

[12] Spalding AR, Burney DP, Richie RE: Acquired benign bronchoesophageal fistulas in the adult. Ann Thorac Surg 1979; 28 379-383. 2.

[13] Kim JH, Park KH, Sung SW, Rho JR: Bronchoesophageal fistulas in adult.

[14] Madan, K., Venkatnarayan, K., Shalimar, \& Mohan, A. (2014). Successful medical management of tuberculous bronchooesophageal fistula. Case Reports, 2014(mar11 2), bcr2013202560bcr2013202560. doi:10.1136/bcr-2013-202560.

[15] Lucaya J, Sole S, Badosa J, Manzanares R: Bronchial perforation and bronchoesophageal fistulas: Tuberculous origin in children. Am J Radiol 1980; 135: 525-528.

[16] Bashi SA, Laajam MB, Joharjy IA, Abdullah AK: Tuberculous oesophagopulmonary communication: Effectiveness of antituberculous chemotherapy. A case report and review of literature. Digestion 1985; 32: 145-148.

[17] Tomiyama K., Ishida H., Miyake M. Benign acquired bronchoesophageal fistula in an adult. Jpn J Thorac Cardiovasc Surg. 2003; 51: 242-245. 